\title{
Development of probability distributions for regional climate change from uncertain global mean warming and an uncertain scaling relationship
}

\author{
B. Hingray ${ }^{1}$, A. Mezghani ${ }^{1}$ and T.A. Buishand ${ }^{2}$ \\ ${ }^{1}$ Laboratory of Hydrology and Land Improvement, Swiss Federal Institute of Technology, Lausanne \\ ${ }^{2}$ Royal Netherlands Meteorological Institute (KNMI), De Bilt, The Netherlands
}

Email address for corresponding author: benoit.hingray@gmail.com

\begin{abstract}
To produce probability distributions for regional climate change in surface temperature and precipitation, a probability distribution for global mean temperature increase has been combined with the probability distributions for the appropriate scaling variables, i.e. the changes in regional temperature/precipitation per degree global mean warming. Each scaling variable is assumed to be normally distributed. The uncertainty of the scaling relationship arises from systematic differences between the regional changes from global and regional climate model simulations and from natural variability. The contributions of these sources of uncertainty to the total variance of the scaling variable are estimated from simulated temperature and precipitation data in a suite of regional climate model experiments conducted within the framework of the EUfunded project PRUDENCE, using an Analysis Of Variance (ANOVA). For the area covered in the 2001-2004 EU-funded project SWURVE, five case study regions (CSRs) are considered: NW England, the Rhine basin, Iberia, Jura lakes (Switzerland) and Mauvoisin dam (Switzerland). The resulting regional climate changes for 2070-2099 vary quite significantly between CSRs, between seasons and between meteorological variables. For all CSRs, the expected warming in summer is higher than that expected for the other seasons. This summer warming is accompanied by a large decrease in precipitation. The uncertainty of the scaling ratios for temperature and precipitation is relatively large in summer because of the differences between regional climate models. Differences between the spatial climate-change patterns of global climate model simulations make significant contributions to the uncertainty of the scaling ratio for temperature. However, no meaningful contribution could sometimes be found for the scaling ratio for precipitation due to the small number of global climate models in the PRUDENCE project and natural variability, which is often the largest source of uncertainty. In contrast, for temperature, the contribution of natural variability to the total variance of the scaling ratio is small, in particular for the annual mean values. Simulation from the probability distributions of global mean warming and the scaling ratio results in a wider range of regional temperature change than that in the regional climate model experiments. For the regional change in precipitation, however, a large proportion of the simulations (about $90 \%$ ) is within the range of the regional climate model simulations.
\end{abstract}

Keywords: uncertainty, regional climate model, temperature, rainfall, scaling, climate change

\section{Introduction}

The possibility of an important climate change in the next decades as a result of anthropogenic increases of greenhouse gases is of great international concern. To assess the potential impacts of climate change on a given water resource system, regional changes in different key meteorological variables such as precipitation and temperature must be characterised. The projections of regional climate changes, based mainly on the results of coupled Atmosphere-Ocean General Circulation Models (AOGCMs), are uncertain; future greenhouse gas emissions are unknown and the models are a highly simplified representation of reality due to imperfect knowledge of some key processes and the need for simplifying complex ones. Crude description of cloud formation, of sea-ice and uncertainty about the magnitude of indirect effects of aerosol forcing are often reported as important sources of uncertainty in model results (IPCC, 2001). Hence, state-of-the-art AOGCMs usually simulate different climate evolutions for the same emission scenario (Arnell and Hulme, 2000; Räisänen, 2001, 2002). Finally, because of their coarse resolution, AOGCMs have a very crude representation of topography. Even the most recent 
models cannot, therefore, give a detailed description of regional features. For a set of 14 AOGCMs, Räisänen (2001) demonstrated that the inter-model agreement on changes in mean temperature or mean precipitation due to a doubling of $\mathrm{CO}_{2}$ depends strongly on the scale of the region of interest. The agreement is rather poor for changes in precipitation at the grid box scale $\left(2.5^{\circ}\right.$ latitude $\times 3.75^{\circ}$ longitude $)$ but it improves when climate changes are averaged over areas larger than grid boxes. Regional Climate Models (RCMs) driven by AOGCMs with a higher spatial resolution $\left(0.5^{\circ}\right.$ latitude $\times 0.5^{\circ}$ longitude or higher $)$ are intended to describe regional features of climatic variables better. RCMs are, however, still based on simplified representations of processes in the atmosphere and at the land surface, using uncertain parameters. For the same AOGCM experiment, the results of regional climate models can, therefore, differ significantly (Frei et al., 2003; Raïsänen et al., 2004).

Evaluating the full range of possible climate changes for a given location or region would thus require analysing and combining effects of emission scenarios, effects of model structures and parameterisations. This would need a very large number of AOGCM-RCM experiments with different emission scenarios. As climate model simulations are highly time consuming, alternative approaches have to be found. Wigley and Raper (2001) recently presented such an approach to determine the full range of global-mean warming from 1990 to different future years. A simple upwelling-diffusion energy balance model was calibrated against the results of seven state-of-the-art AOGCMs. The uncertainties in emissions, the sensitivity of the climate system to radiative forcing (i.e. the 'climate sensitivity', characterised by the equilibrium global-mean warming for a doubling of the $\mathrm{CO}_{2}$ level), carbon cycle, ocean vertical diffusivity and aerosol forcing were represented by appropriate Probability Density Functions which drove the simple climate model, resulting in Probability Density Functions of global-mean warming.

The approach presented in the present paper aims to evaluate the Probability Density Functions of climate changes for different regions across Europe, accounting for the full range of global-mean warming. It is based on the assumption that a simple scaling relationship exists between regional climate changes and global-mean warming. For the changes in regional meteorological variables, this scaling is usually expressed in terms of a ratio describing the absolute or the relative regional changes per degree globalmean warming (Jones, 2000). The uncertainty of this scaling relationship has been characterised by the range of regional changes per degree of global-mean warming in a set of AOGCMs (Whetton et al., 1996) or RCM-AOGCMs (Ekström et al., 2007). Here, this uncertainty is assessed with an analysis of variance of the results from a set of AOGCM-RCM experiments provided by the EU-funded project PRUDENCE (Christensen et al., 2002). The Probability Density Functions of regional changes are next obtained by combining a Probability Density Function of global mean warming derived from Wigley and Raper (2001) with Probability Density Functions from the scaling analysis. This research has been conducted within the 2001-2004 EU-funded project SWURVE (Sustainable Water, Uncertainty, Risk and Vulnerability in Europe) where the impact of climate change on specific water management activities is analysed. The methodology is illustrated with results obtained for the five SWURVE case study regions (Kilsby, 2007).

The paper describes the datasets used in this study, the scaling relationships between regional mean changes and global mean warming obtained from the datasets and evaluation of the uncertainty of these relationships. Details on the methodology are given for the Mauvoisin case study region located in the Swiss Alps (Lat: $46.25^{\circ}$ - Long: $7.25^{\circ}$ ) (Schaefli et al., 2007). Finally, Probability Density Functions of regional changes for seasonal and annual mean temperature and precipitation are presented for the five SWURVE case study regions (CSRs).

\section{Datasets}

Each RCM experiment comprises a simulation for the period 1961-1990 (control run) and a simulation for the period 2070-2099 (future run). Boundary conditions were obtained from the three AOGCMs used in the PRUDENCE project: ARPEGE/OPA (Royer et al., 2002), HadCM3 (Gordon et al., 2000; Pope et al., 2000) and ECHAM4/OPYC3 (Roeckner et al., 1999). In the case of HadCM3, a global model of the atmosphere alone (HadAM3H) was used between the global coupled model and the RCMs; this intermediate model resulted in a much better simulation of the present-day climate (Hulme et al., 2002). The AOGCM experiments were done both with SRES A2 and SRES B2 emission scenarios (Nakicenovic and Swart, 2000).

In the present study, nine RCMs are included (Table 1). One of these models, ARPEGE, is, however, not a regional but a global atmospheric model with variable horizontal resolution, from $50 \mathrm{~km}$ in the centre of the Mediterranean Sea to $450 \mathrm{~km}$ in the southern Pacific Ocean (Gibelin and Déqué, 2003). In PRUDENCE, the low boundary conditions (sea-surface temperatures, sea-ice) were obtained from ARPEGE/OPA (Déqué, pers. comm.). For the five SWURVE CSRs, the horizontal resolution is comparable to that of the other RCMs. ARPEGE is considered further as an RCM in this paper. Some RCMs were run successively 
Table 1. (a) The three AOGCM and (b) the nine RCM models used in the PRUDENCE project (Christensen et al., 2002) and the corresponding institutions.

\begin{tabular}{|c|c|c|c|}
\hline Acronym & Institution & $A O G C M$ & Reference \\
\hline \multicolumn{4}{|l|}{ (a) } \\
\hline CNRM & Centre National de Recherches Météorologiques, Toulouse, France & ARPEGE/OPA & Royer et al. (2002) \\
\hline $\mathrm{HC}$ & Hadley Centre for Climate Prediction and Research, Exeter, UK & HadCM3 & $\begin{array}{l}\text { Gordon et al. (2000) } \\
\text { Pope et al. (2000) }\end{array}$ \\
\hline MPI & Max-Planck-Institut für Meteorologie, Hamburg, Germany & ECHAM4/OPYC3 & Roeckner et al. (1999) \\
\hline \multicolumn{4}{|l|}{ (b) } \\
\hline CNRM & Centre National de Recherches Météorologiques, Toulouse, France & ARPEGE & Gibelin and Déqué (2003) \\
\hline DMI & Danish Meteorological Institute, Copenhagen, Denmark & HIRHAM & Christensen et al. (2001) \\
\hline ETHZ & Institute for Atmospheric and Climate Science, Zürich, Switzerland & CHRM & Vidale et al. (2003) \\
\hline GKSS & Institute for Coastal Research, Geesthacht, Germany & CLM & Doms and Schättler (1999) \\
\hline $\mathrm{HC}$ & Hadley Centre for Climate Prediction and Research, Exeter, UK & HadRM3H & Hulme et al. (2002) \\
\hline ICTP & International Centre for Theoretical Physics, Trieste, Italy & $\mathrm{RegCM}$ & Giorgi et al. (1993ab) \\
\hline KNMI & Royal Netherlands Meteorological Institute, De Bilt, The Netherlands & RACMO & Lenderink et al. (2003) \\
\hline MPI & Max-Planck-Institut für Meteorologie, Hamburg, Germany & REMO & $\operatorname{Jacob}(2001)$ \\
\hline SMHI & Swedish Meteorological and Hydrological Institute, Norrköping, Sweden & RCAO & Räisänen et al. (2004) \\
\hline UCM & Universidad Complutense de Madrid, Toledo, Spain & PROMES & Arribas et al. (2003) \\
\hline
\end{tabular}

using the boundary conditions of different AOGCMs. All RCMs were run at least for scenario A2 with one AOGCM. Some RCMs were also run for scenario B2. For this study, 19 experiments were available, 12 of those for scenario A2 and 7 for scenario B2. The synthesis of these experiments is given in Table 2 .

The 30-year seasonal means of surface air temperature and precipitation were produced within the PRUDENCE project over the whole European domain on a common $0.5^{\circ}$ latitude $\times 0.5^{\circ}$ longitude grid. The regional seasonal (and annual) mean values are denoted as $M T$ for temperature and $M P$ for precipitation. For 12 experiments, indicated by a star in Table 2, the seasonal values for the individual years were obtained.

To be compatible with the usual requirements of hydrological applications, regional changes are expressed in terms of absolute changes $\left(X M T=M T_{\text {future }}-M T_{\text {control }}\right)$ for seasonal mean temperatures and in terms of relative changes $\left(X M P=M P_{\text {future }} / M P_{\text {control }}-1\right)$ for seasonal mean precipitation. For the relatively small Mauvoisin CSR, the mean change of 20 grid boxes was considered rather than that of the single grid box encompassing the study region. Though RCMs are reported to reproduce well the regional features of meteorological surface variables such as precipitation and temperature (Frei et al., 2003), they are less reliable for each individual grid box, in particular in mountainous regions. It is, therefore, highly recommended that several grid boxes are considered for hydrological applications (Christoph Frei,
Table 2. Clusters of RCM experiments according to driving AOGCM and to emission scenario. All RCM experiments were conducted in the framework of PRUDENCE. Time series of seasonal values were obtained for all RCMs marked with a star, otherwise, only the 30-year averages were considered.

\begin{tabular}{|c|c|c|c|c|c|}
\hline $\begin{array}{l}\text { Scenario } \\
\text { Name }\end{array}$ & $N^{\circ}$ & $\begin{array}{l}\text { AOGCM } \\
\text { Name }\end{array}$ & $N^{\circ}$ & $\begin{array}{l}\text { RCM } \\
\text { Name }\end{array}$ & $N^{\circ}$ \\
\hline \multirow[t]{12}{*}{ A2 } & \multirow[t]{12}{*}{1} & HadCM3 & \multirow[t]{9}{*}{1} & CHRM* & 1 \\
\hline & & HadCM3 & & CLM & 2 \\
\hline & & HadCM3 & & HadRM3H & 3 \\
\hline & & HadCM3 & & HIRHAM* & 4 \\
\hline & & HadCM3 & & PROMES & 5 \\
\hline & & HadCM3 & & $\mathrm{RCAO}(\mathrm{H})^{*}$ & 6 \\
\hline & & HadCM3 & & RegCM* & 7 \\
\hline & & HadCM3 & & REMO* & 8 \\
\hline & & HadCM3 & & RACMO* & 9 \\
\hline & & ARPEGE/OPA & 2 & ARPEGE & 10 \\
\hline & & ECHAM4/OPYC3 & \multirow[t]{2}{*}{3} & HIRHAM* & 11 \\
\hline & & ECHAM4/OPYC3 & & $\mathrm{RCAO}(\mathrm{E})^{*}$ & 12 \\
\hline \multirow[t]{7}{*}{ B2 } & \multirow[t]{7}{*}{2} & HadCM3 & \multirow[t]{4}{*}{4} & HadRM3H & 13 \\
\hline & & HadCM3 & & PROMES & 14 \\
\hline & & HadCM3 & & $\mathrm{RCAO}(\mathrm{H})^{*}$ & 15 \\
\hline & & HadCM3 & & $\operatorname{RegCM} *$ & 16 \\
\hline & & ARPEGE/OPA & 5 & ARPEGE & 17 \\
\hline & & ECHAM4/OPYC3 & \multirow[t]{2}{*}{6} & HIRHAM* & 18 \\
\hline & & ECHAM4/OPYC3 & & $\operatorname{RCAO}(\mathrm{E})^{*}$ & 19 \\
\hline
\end{tabular}




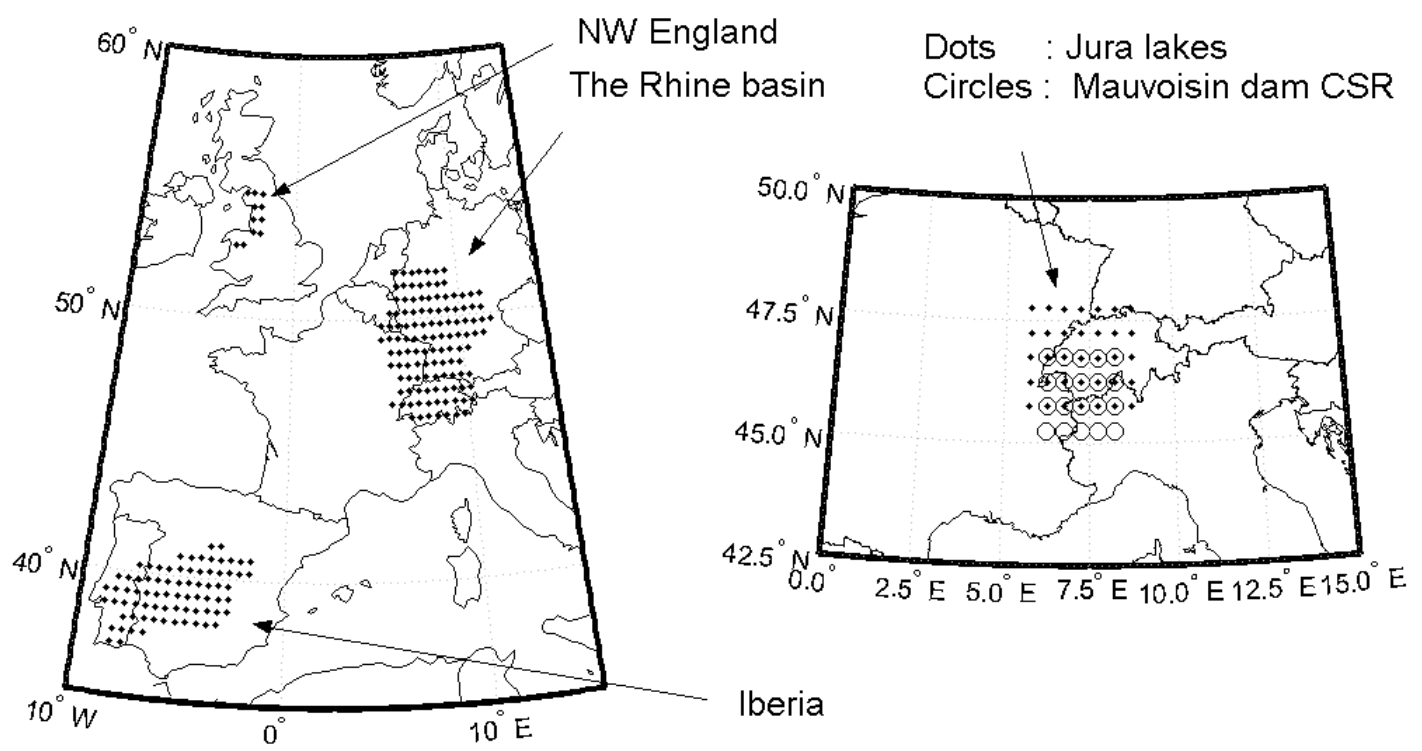

Fig. 1. Location of selected regions in the regular PRUDENCE grid for the five SWURVE case study regions $\left(0.5^{\circ}\right.$ latitude by $0.5^{\circ}$ longitude) (from Ekström et al., 2007).

Table 3. Description of the five case study regions (see Kilsby, 2007 , for details) The number of grid boxes refers to the $0.5^{\circ} \times 0.5^{\circ}$ grid of the PRUDENCE data.

\begin{tabular}{llc}
\hline Acronym & Case Study Region (CSR) & $N^{\circ}$ of grid boxes \\
\hline NWE & North West England & 11 \\
RH & The Rhine Basin & 118 \\
IB & Iberia & 76 \\
JL & Jura Lakes System & 35 \\
MA & Mauvoisin Dam & 20 \\
\hline
\end{tabular}

pers. comm.). For the other CSRs, regional changes were averaged over the grid boxes encompassing the region of interest (Fig. 1 and Table 3).

\section{Linear relationships between regional climate changes and global mean warming}

The global mean warming predicted by the three AOGCMs varies from 2.35 to $2.76{ }^{\circ} \mathrm{C}$ for scenario B2 and from 3.02 to $3.56{ }^{\circ} \mathrm{C}$ for scenario A2 (Table 4). For these 'emissionscenario AOGCM' configurations, the ratio between the highest and the lowest warming projection is thus 1.5. Regional climate change is usually more variable (Arnell and Hulme, 2000; Räisänen, 2001; Räisänen, 2002). For each of the five CSRs, the ratio between the highest and lowest regional warming in the PRUDENCE dataset is about 2.5 .
The regional change predictions obtained from the PRUDENCE RCM experiments are conditioned by the six different 'emission-scenario AOGCM' experiments listed in Table 2. These driving models do not account fully for the uncertainties of the global mean warming. The global mean warming range of the six 'emission-scenario AOGCM' experiments covers, for example, only $45 \%$ of the $90 \%$ probability interval of the 1990 to $2070-2100$ global mean warming based on the results of Wigley and Raper (2001) for the years 2070, 2080, 2090 and 2100 (kindly provided by Tom Wigley). The lowest (resp. highest) global mean warming projection of these experiments corresponds to the 40th (resp. 85th) percentile of the derived global mean warming distribution for 2070-2100. Thus, the lower range of the global mean warming is not captured by the AOGCMs in the PRUDENCE project mainly because of their relatively high sensitivity to radiative forcing. The variability of the regional changes in the PRUDENCE dataset might, therefore, not be representative of that obtained from a larger set of AOGCM and emission scenario experiments.

To assess the uncertainty of regional precipitation and temperature changes, it has been assumed, as is frequently done, that regional changes are a linear function of global mean warming. Then, using any available Probability Density Function of global mean warming, it becomes possible to produce the Probability Density Function of regional changes using Monte Carlo simulations (Jones, 2000). For the Mauvoisin CSR, the relationship between the regional changes (for winter and summer) and global mean warming is shown in Fig. 2. The hypothesis of linearity seems to hold well for temperature. For precipitation, the 
Table 4. Change $\Delta T$ in the global mean temperature between 1961-1990 and 2070-2099 for the two SRES scenarios A2 and B2 as obtained with the three AOGCMs used in the PRUDENCE project.

\begin{tabular}{llcc}
\hline AOGCM & Reference & $\Delta T-A 2\left({ }^{\circ} \mathrm{C}\right)$ & $\Delta T-B 2\left({ }^{\circ} \mathrm{C}\right)$ \\
\hline HadCM3 & Gordon et al. $(2000)$ & 3.25 & 2.39 \\
ARPEGE/OPA & Gibelin and Déqué (2003) & 3.02 & 2.35 \\
ECHAM4/OPYC3 & Roeckner et al. (1999) & 3.56 & 2.76 \\
\hline
\end{tabular}

relationship is much weaker, although still significant at the $5 \%$ level. The estimate of the slope in Fig. 2 represents the mean regional change per degree global warming. In fact, each of the $19 \mathrm{RCM}$ experiments provides a value of this scaling ratio. The variance of the individual scaling ratios is a suitable measure of the uncertainty of the scaling relationship.

\section{Estimating uncertainty in the scaling relationship}

THEORETICAL FRAMEWORK

In this section the following scaling ratios are studied:

$$
\begin{aligned}
& Y M T_{s}=X M T_{s} / \Delta T \\
& Y M P_{s}=X M P_{s} / \Delta T
\end{aligned}
$$

where $\Delta T$ is the global mean warming expressed in ${ }^{\circ} \mathrm{C}$ and where $s$ refers to the period $(s=0$ : annual; $s=1$ : DJF; $s=2$ : MAM; $s=3:$ JJA; $s=4: \mathrm{SON})$. Note that $Y M T$ is dimensionless and $Y M P$ is expressed in ${ }^{\circ} \mathrm{C}^{-1}$.

Both for precipitation and temperature, no dependence between the 19 scaling ratios and global mean warming could be detected (Fig. 3). Though the emission scenario and the driving model are usually expected to give the largest contribution to the regional climate-change uncertainty (Giorgi and Mearns, 2002), Fig. 3 shows that scaling ratios obtained from different RCMs driven by the same AOGCM can also be very variable. The contribution of RCMs to the regional climate-change uncertainty cannot, thus, be neglected a priori. Another source of uncertainty is the natural variability of a 30-year mean.

Only experiments with the SRES A2 and B2 emission scenarios are available from the PRUDENCE dataset. It is assumed that the linear trend highlighted in Fig. 3 would remain under other emission scenarios.

For both the $\mathrm{A} 2$ and $\mathrm{B} 2$ emission scenarios, a limited number of AOGCM simulations were considered in the
PRUDENCE project and, for each AOGCM simulation, a limited number of RCM experiments were conducted. It is assumed that the scaling ratios from the available set of experiments are representative of the scaling ratios that could be obtained from an infinite population of AOGCM-RCM experiments. However, even with these drastic assumptions, estimating the uncertainty of the scaling ratios $Y M T$ and $Y M P$ is not straightforward for three main reasons:

(1) The dataset can be partitioned into different classes and subclasses. RCM experiments driven by the same AOGCM are expected to give similar results and have thus to be clustered according to the driving AOGCM. These AOGCM clusters should for the same reason be clustered again according to the emission scenario (see clusters in Table 2).

(2) The number of experiments can be very different from one cluster to the other (for example: nine experiments in the cluster HadCM3-A2, two experiments in the cluster ECHAM4/OPYC3-A2; twelve and seven experiments for $\mathrm{A} 2$ and $\mathrm{B} 2$ respectively).

(3) Different experiments obtained with a different driving AOGCM but the same RCM may show similarity as the same parameterisations are used for regional modelling.

An ANalysis Of VAriance (ANOVA) was used to estimate the uncertainty of the scaling relationships (Searle, 1997) making the following assumptions:

- H1: Scaling relationships that could be obtained independently for emission scenarios A2 and B2 have the same occurrence probability.

- H2: All AOGCM models as well as all RCM models perform equally well. Although this is probably not the case, it is the simplest assumption to make.

- H3: Instead of considering that the two emission scenarios and the three AOGCMs produce two levels of uncertainty, it is reasonable to consider that the six 'emission-scenario AOGCM' configurations belong to 

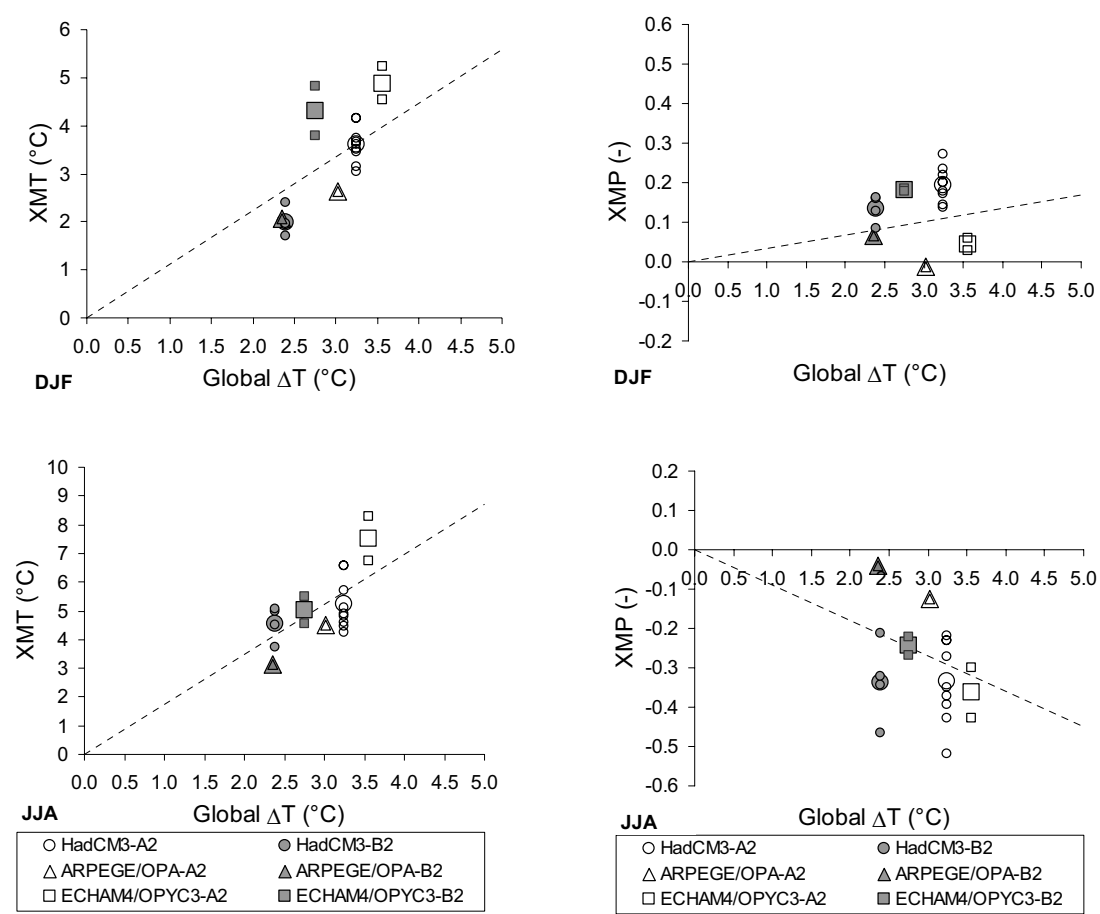

Fig. 2. Scaling relationships between regional climate changes and global mean warming for the Mauvoisin CSR (Lat: 46.25; Long: 7.25). Left: regional temperature changes, right: regional precipitation changes. Top: winter season, bottom: summer season ( $\triangle T$ is not specific for a given season). Symbol shape indicates the driving AOGCM (squares: ECHAM4/OPYC3; triangles: ARPEGE/OPA (circles: HadCM3). Symbol colour indicates the emission scenario (gray for B2 - white for A2). Each small sized symbol corresponds to one RCM experiment. Large sized symbols correspond to the centroid of each AOGCM group. The straight lines are based on a least-squares fit to the mean values of the six AOGCM clusters. Linear regressions were forced to pass through the origin
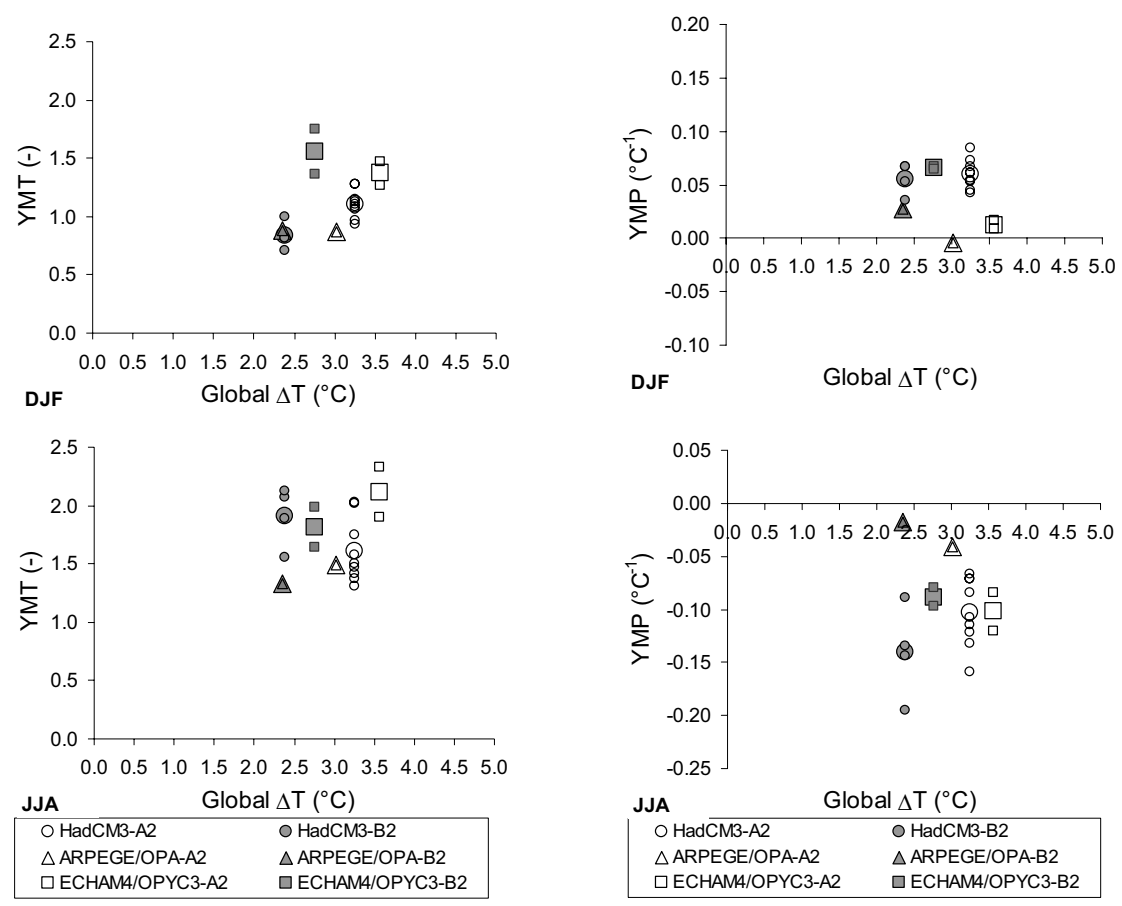

Fig. 3. Scaling ratio as a function of global mean warming for seasonal mean temperature change (YMT) and for seasonal mean precipitation change (YMP). Results for the Mauvoisin CSR. Top: winter season, bottom: summer season. For further details, see Fig. 2 caption . 
a unique super-ensemble. Scaling ratios obtained for the A2 and B2 emission scenarios did not reveal significant differences (Fig. 3). Moreover, the differences between the scaling ratios for the two emission scenarios were of magnitudes similar to those observed between the three different AOGCMs for a given emission scenario.

It is furthermore assumed that the seasonal (resp. annual) scaling ratio $\left(Y M T_{s}\right.$ or $Y M P_{s} ; s=0, \ldots, 3$ or 4$)$ can be expressed as:

$$
y_{i j}=\mu+a_{i}+b_{j}+e_{i j}\left\{\begin{array}{l}
i=1,2, \ldots, A \\
j=1,2, \ldots, B
\end{array}\right.
$$

with $A$ the number of 'emission-scenario AOGCM' configurations ( $A=6$ in the present study), $B$ the number of RCMs in the PRUDENCE ensemble $(B=10), \mu$ an unknown constant, $a_{i}$ a deviation related to the particular 'emission-scenario AOGCM' configuration, $b_{j}$ a deviation associated with the RCM, and $e_{i j}$ a noise term that accounts for the natural variability of a 30-year mean. It is assumed that the $a_{i}, b_{j}$ and $e_{i j}$ have zero mean and variances $\sigma_{a}^{2}, \sigma_{b}^{2}$ and $\sigma_{e}^{2}$, respectively. A possible dependence of $\sigma_{e}^{2}$ on $\Delta T$ has been explored.

The number of experiments with the $j$ th RCM in the $i$ th 'emission-scenario AOGCM' configuration is indicated as $n_{i j}$. Although three out of the 19AOGCM-RCM experiments in Table 2 were repeated twice with different initial conditions, only one ensemble member was considered. So $n_{i j}=0$ or 1 .

Assuming that the three random variables on the righthand side of Eqn. (3) are independent, the variance $\sigma_{y}^{2}$ of $y$ is given by:

$$
\sigma_{y}^{2}=\sigma_{a}^{2}+\sigma_{b}^{2}+\sigma_{e}^{2}
$$

The mean $\mu$ and the total variance $\sigma_{y}^{2}$ characterise the magnitude and uncertainty of the scaling variable.

Equation (3) represents a two-way crossed classification (Searle, 1997). The fact that the number of RCM experiments varies over the 'emission-scenario AOGCM' clusters makes the ANOVA unbalanced. A further complication is that seasonal temperatures and precipitation from two RCMs driven by the same AOGCM boundaries are strongly correlated causing a correlation between the corresponding $e_{i j}$. Because of this correlation, the statistical techniques for estimating the variance components $\sigma_{a}^{2}, \sigma_{b}^{2}$ and $\sigma_{e}^{2}$ in a two-way crossed classification cannot be used. In this study, the variances and correlations of the $e_{i j}$ were derived from the 12 experiments for which the seasonal values of temperature and precipitation were available
(Appendix A). Estimates of $\sigma_{a}^{2}$ and $\sigma_{b}^{2}$ were then obtained from the following sums of squares:

$$
\begin{aligned}
& S S_{1}=\sum_{i=1}^{A} n_{i \bullet}\left(\frac{y_{i \bullet}}{n_{i \bullet}}-\frac{y_{\bullet \bullet}}{n}\right)^{2}=\sum_{i=1}^{A} \frac{y_{i \bullet}^{2}}{n_{i \bullet}}-\frac{y_{\bullet \bullet}^{2}}{n} \\
& S S_{2}=\sum_{i=1}^{A} \sum_{j=1}^{B} n_{i j}\left(y_{i j}-\frac{y_{i \bullet}}{n_{i \bullet}}\right)^{2}=\sum_{i=1}^{A} \sum_{j=1}^{B} n_{i j} y_{i j}^{2}-\sum_{i=1}^{A} \frac{y_{i \bullet}^{2}}{n_{i \bullet}}
\end{aligned}
$$

with $n_{i \bullet}=\sum_{j=1}^{B} n_{i j}$ the number of RCM simulations in the $i$ th 'emission-scenario AOGCM' cluster, $n$ the total number of RCM simulations

$$
n=\sum_{i=1}^{A} n_{i \bullet}=\sum_{i=1}^{A} \sum_{j=1}^{B} n_{i j}
$$

and

$$
y_{i \bullet}=\sum_{j=1}^{B} n_{i j} y_{i j}, \quad y_{\bullet \bullet}=\sum_{i=1}^{A} y_{i \bullet}
$$

Details are given in Appendix B. As Eqns. (5) and (6) may yield a negative estimate of $\sigma_{a}^{2}$ or $\sigma_{b}^{2}$, in that case the variance component was set to zero. From the $12 \mathrm{RCM}$ experiments used for estimating $\sigma_{e}^{2}$, no systematic relationship could be found between the variances $\sigma_{N}^{2}$ of the regional mean changes $\left(X M T_{s}\right.$ and $\left.X M P_{s}\right)$ and global mean warming. Figure 4 demonstrates this for the Mauvoisin CSR. Though there is some dependence of the variance of the regional mean changes on the 'emission-scenario AOGCM' configuration, no general trend can be identified. It was, therefore, assumed that $\sigma_{N}^{2}$ is constant. In line with this, the variance of $e_{i j}$ should be inversely proportional to the square of the global temperature change $\Delta T_{i}$ (Appendix A), i.e. . $\sigma_{e, i}^{2}=\operatorname{var}\left(e_{i j}\right)=\sigma_{N}^{2} /\left(\Delta T_{i}^{2}\right)$

Finally, the parameter $\mu$ was estimated as a weighted average of the means $\bar{y}_{i \bullet}=y_{i \bullet} / n_{i \bullet}$ of the 'emission-scenario AOGCM' clusters. The weights were taken to be inversely proportional to $\operatorname{var}\left(\bar{y}_{i \bullet}\right)$.

\section{ANOVA RESULTS}

Results of the analysis of variance are given for the annual and seasonal scaling variables $Y M T$ and $Y M P$. For each CSR, Table 5 presents the estimates of $\mu$ and the variances of the random components in Eqn. (3). The estimate of $\sigma_{e}^{2}$ in this table is a weighted average of the estimates $\hat{\sigma}_{e, i}^{2}$ for the different 'emission-scenario AOGCM' clusters:

$$
\hat{\sigma}_{e}^{2}=\frac{1}{n} \sum_{i=1}^{A} n_{i \bullet} \hat{\sigma}_{e, i}^{2}
$$

The pooled estimate of $\sigma_{y}^{2}$ in Table 5 was derived from 
Table 5. Statistics of seasonal and annual scaling ratios obtained from ANOVA for the five SWURVE CSRs (statistics relate to the 19 PRUDENCE RCM experiments). $\mu$ : mean scaling ratio (dimensionless for temp.; ${ }^{\circ} \mathrm{C}^{-1}$ for prec.), $\sigma_{y}^{2}, \sigma_{e}^{2}, \sigma_{b}^{2}, \sigma_{a}^{2}$ : total variance of scaling ratio, variance due to the natural variability contribution, to the RCM contribution and to the 'emission-scenario AOGCM' contribution, respectively (dimensionless for temp.; ${ }^{\circ} \mathrm{C}^{-2}$ for prec.) and $\rho_{e, 1}$ : correlation coefficient between the contributions of the natural variability for the RCM simulations in the HadCM3-A2 cluster. Values for which $\mu$ differs more than $2 \times \sigma_{y}$ from 1 for temperature or from 0 for precipitation are printed in bold and underlined.

\begin{tabular}{|c|c|c|c|c|c|c|c|c|c|c|c|}
\hline & & \multicolumn{5}{|c|}{$\begin{array}{l}\text { Absolute temperature change } \\
\text { per degree global mean warming }\end{array}$} & \multicolumn{5}{|c|}{$\begin{array}{l}\text { Relative precipitation change } \\
\text { per degree global mean warming }\end{array}$} \\
\hline & & $A N N U A L$ & $D J F$ & $M A M$ & $J J A$ & SON & $A N N U A L$ & $D J F$ & $M A M$ & $J J A$ & $S O N$ \\
\hline \multirow[t]{6}{*}{ NWE } & $\mu$ & 0.890 & 0.695 & 0.787 & 1.047 & 1.045 & 0.0109 & $\underline{0.0701}$ & 0.0057 & -0.0757 & 0.0233 \\
\hline & $\sigma_{y}^{2}$ & 0.041 & 0.058 & 0.062 & 0.050 & 0.021 & 0.00034 & 0.00084 & 0.00065 & 0.00153 & 0.00080 \\
\hline & $\sigma_{b}^{2}$ & 0.007 & 0.001 & 0.005 & 0.029 & 0.006 & 0.00012 & 0.00022 & 0.00019 & 0.00012 & 0.00019 \\
\hline & $\sigma_{q}^{2}$ & 0.033 & 0.050 & 0.052 & 0.017 & 0.012 & 0.00009 & 0.00000 & 0.00000 & 0.00109 & 0.00006 \\
\hline & $\sigma_{e}^{2}$ & 0.002 & 0.006 & 0.006 & 0.005 & 0.004 & 0.00013 & 0.00062 & 0.00047 & 0.00032 & 0.00055 \\
\hline & $\rho_{e, 1}$ & 0.91 & 0.94 & 0.90 & 0.86 & 0.82 & 0.87 & 0.93 & 0.79 & 0.83 & 0.86 \\
\hline \multirow[t]{6}{*}{ RH } & $\mu$ & 1.239 & 1.051 & 1.028 & 1.601 & 1.302 & -0.0135 & $\underline{0.0524}$ & -0.0108 & -0.0814 & -0.0183 \\
\hline & $\sigma_{y}^{2}$ & 0.061 & 0.074 & 0.076 & 0.177 & 0.033 & 0.00023 & 0.00066 & 0.00075 & 0.00191 & 0.00046 \\
\hline & $\sigma_{b}^{2}$ & 0.025 & 0.013 & 0.012 & 0.121 & 0.018 & 0.00012 & 0.00001 & 0.00006 & 0.00079 & 0.00012 \\
\hline & $\sigma_{a}^{2}$ & 0.033 & 0.047 & 0.052 & 0.043 & 0.007 & 0.00000 & 0.00000 & 0.00039 & 0.00084 & 0.00000 \\
\hline & $\sigma_{e}^{2}$ & 0.004 & 0.014 & 0.012 & 0.013 & 0.007 & 0.00011 & 0.00064 & 0.00031 & 0.00029 & 0.00035 \\
\hline & $\rho_{\mathrm{e}, 1}$ & 0.86 & 0.91 & 0.86 & 0.77 & 0.75 & 0.82 & 0.94 & 0.78 & 0.74 & 0.78 \\
\hline \multirow[t]{6}{*}{ IB } & $\mu$ & 1.351 & 0.979 & 1.287 & $\underline{1.805}$ & 1.358 & $\underline{-0.0671}$ & 0.0127 & $\underline{-0.1180}$ & -0.1292 & $\underline{-0.0886}$ \\
\hline & $\sigma_{y}^{2}$ & 0.041 & 0.045 & 0.085 & 0.054 & 0.050 & 0.00063 & 0.00273 & 0.00146 & 0.00466 & 0.00086 \\
\hline & $\sigma_{b}^{2}$ & 0.011 & 0.009 & 0.016 & 0.024 & 0.007 & 0.00010 & 0.00000 & 0.00045 & 0.00084 & 0.00000 \\
\hline & $\sigma_{q}^{2}$ & 0.027 & 0.030 & 0.054 & 0.022 & 0.037 & 0.00000 & 0.00000 & 0.00000 & 0.00287 & 0.00000 \\
\hline & $\sigma_{e}^{2}$ & 0.003 & 0.005 & 0.014 & 0.008 & 0.006 & 0.00053 & 0.00273 & 0.00101 & 0.00095 & 0.00086 \\
\hline & $\rho_{e, 1}$ & 0.91 & 0.90 & 0.96 & 0.85 & 0.86 & 0.96 & 0.99 & 0.94 & 0.73 & 0.85 \\
\hline \multirow[t]{6}{*}{ JL } & $\mu$ & 1.308 & 1.088 & 1.110 & 1.752 & 1.319 & -0.0229 & 0.0384 & -0.0186 & $\underline{-0.0937}$ & -0.0318 \\
\hline & $\sigma_{y}^{2}$ & 0.061 & 0.082 & 0.093 & 0.165 & 0.034 & 0.00034 & 0.00084 & 0.00120 & 0.00196 & 0.00039 \\
\hline & $\sigma_{b}^{2}$ & 0.022 & 0.015 & 0.011 & 0.104 & 0.016 & 0.00019 & 0.00001 & 0.00018 & 0.00100 & 0.00000 \\
\hline & $\sigma_{q}^{2}$ & 0.035 & 0.054 & 0.070 & 0.047 & 0.010 & 0.00002 & 0.00000 & 0.00070 & 0.00068 & 0.00000 \\
\hline & $\sigma_{e}^{2}$ & 0.004 & 0.013 & 0.013 & 0.014 & 0.008 & 0.00013 & 0.00083 & 0.00033 & 0.00029 & 0.00039 \\
\hline & $\rho_{e, 1}$ & 0.87 & 0.92 & 0.87 & 0.79 & 0.74 & 0.83 & 0.93 & 0.79 & 0.69 & 0.74 \\
\hline \multirow[t]{6}{*}{ MA } & $\mu$ & 1.331 & 1.119 & 1.173 & $\underline{1.745}$ & 1.321 & -0.0257 & 0.0335 & -0.0247 & -0.0902 & -0.0346 \\
\hline & $\sigma_{y}^{2}$ & 0.055 & 0.084 & 0.098 & 0.110 & 0.037 & 0.00039 & 0.00098 & 0.00129 & 0.00209 & 0.00042 \\
\hline & $\sigma_{b}^{2}$ & 0.017 & 0.017 & 0.009 & 0.067 & 0.017 & 0.00025 & 0.00003 & 0.00024 & 0.00104 & 0.00000 \\
\hline & $\sigma_{q}^{2}$ & 0.034 & 0.054 & 0.076 & 0.031 & 0.013 & 0.00001 & 0.00000 & 0.00074 & 0.00078 & 0.00000 \\
\hline & $\sigma_{e}^{2}$ & 0.004 & 0.013 & 0.013 & 0.012 & 0.007 & 0.00014 & 0.00094 & 0.00032 & 0.00027 & 0.00042 \\
\hline & $\rho_{e, 1}$ & 0.87 & 0.91 & 0.87 & 0.79 & 0.74 & 0.85 & 0.94 & 0.78 & 0.66 & 0.71 \\
\hline
\end{tabular}

Eqn. (4) by substituting $\hat{\sigma}_{e}^{2}$ for $\sigma_{e}^{2}$. The table further presents the estimates of the correlation coefficient, $\rho_{e, 1}$, between the $e_{i j}$ for the HadCM3-A2 cluster. Similar values were obtained for the HadCM3-B2 cluster. The correlations for the ECHAM4/OPYC3 cluster are, however, only about half those for the HadCM3-A2 cluster because the two RCMs in that cluster were nested in two different simulations of ECHAM4/OPYC3 for the 2070-2100 climate (Ole Christensen, pers. comm.).

\section{Results for temperature}

Table 5 shows that, for the annual mean temperature, the mean scaling ratio is larger than 1 for the Rhine basin, Iberia and the Swiss CSRs, implying that the temperature increase in these regions tends to be larger than the expected global mean warming. The value of the estimated standard deviation $\hat{\sigma}_{y}$ (roughly about 0.2 for all CSRs) is, however, such that a regional temperature increase smaller than the expected global mean warming is possible. In contrast to the other CSRs, the expected annual temperature increase 

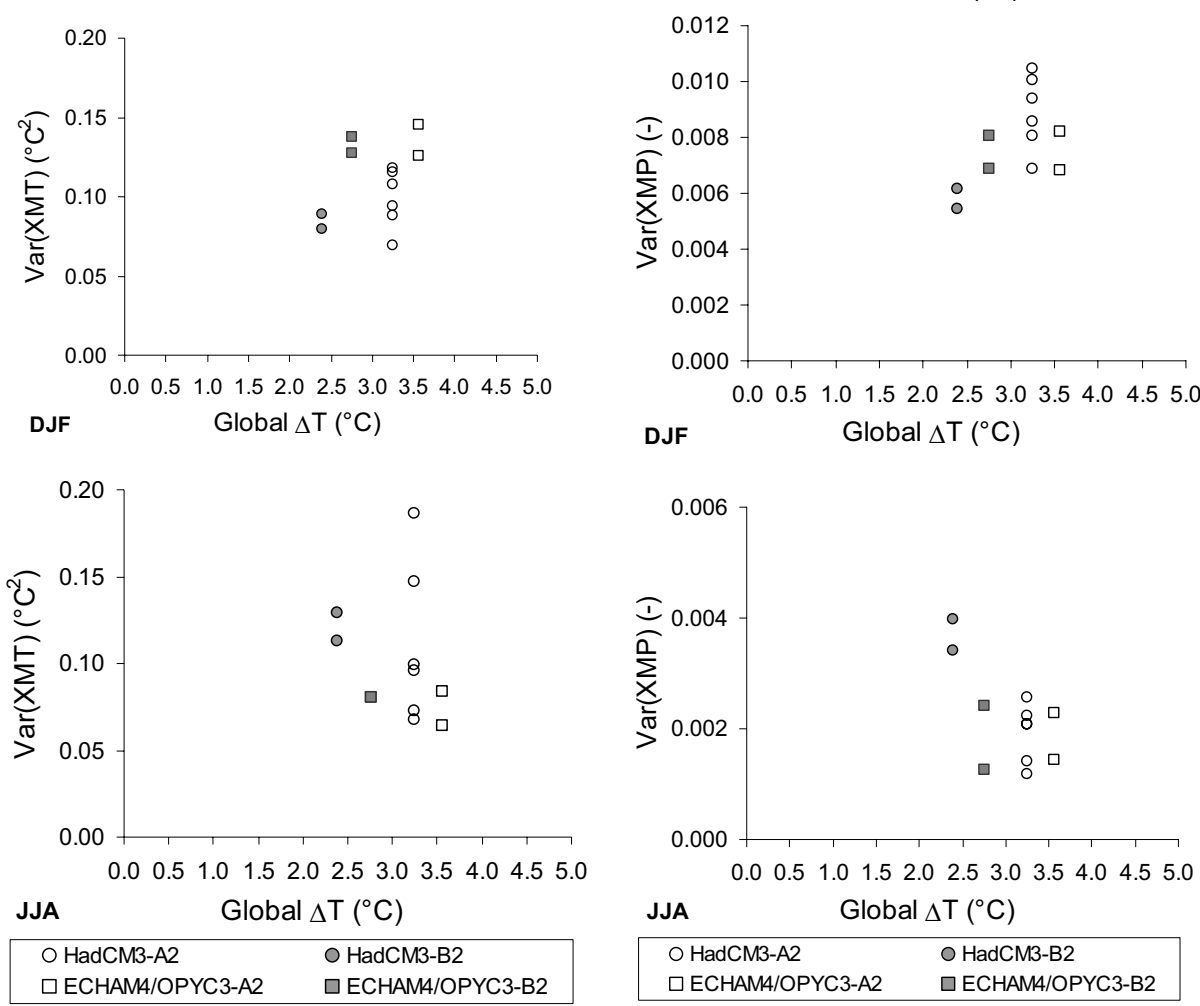

Fig. 4. Variance of changes in the seasonal mean as a function of global mean warming for regional temperature (Var(XMT)) and precipitation $(\operatorname{Var}(X M P))$. Results for the Mauvoisin CSR. Each symbol corresponds to one RCM experiment marked with a star in Table 2. Top: winter season, bottom: summer season. See the caption of Figure 2 for further details and Appendix A for variance estimation.

in the NWE CSR is smaller than that expected for the global mean temperature. An annual temperature increase larger than the expected global mean warming is, however, also possible for NWE. Regional warming is expected to be larger for summer than for autumn and larger for autumn than for winter and spring. The regional warming for NWE in winter and spring is expected to be substantially less than global mean warming. For the other four CSRs, the expected summer warming is much higher than the global mean warming. For three of them (the Rhine basin, Jura lakes and Mauvoisin), the relatively large mean scaling ratio is accompanied by a large value of the standard deviation $\sigma_{y}$. The values of $\sigma_{b}^{2}$ suggest that much of this uncertainty is induced by the differences between RCMs; this is also the case for the uncertainty of the scaling ratios for the autumn season. The contribution of $\sigma_{b}^{2}$ to the total variance $\sigma_{y}^{2}$ is small for winter and spring. Systematic differences between the AOGCMs give a substantial contribution to $\sigma_{y}^{2}$. The values of $\sigma_{a}^{2}$ are relatively large for spring and small for autumn. However, the estimate of $\sigma_{a}^{2}$ is unreliable due to the small number of AOGCMs included in the PRUDENCE ensemble. Natural variability contributes only a small part to the total variance, in particular to that of the annual mean temperature. There is a rather strong correlation between the $e_{i j}$ of the HadCM3-A2 cluster. The largest values of $\rho_{e, 1}$ are found in the winter and spring seasons.

\section{Results for precipitation}

The mean scaling ratio in Table 5 indicates that annual mean precipitation is expected to decrease in the Rhine basin, Iberia and the Swiss CSRs and increases in the NWE CSR. For the Iberian CSR the mean differs more than $2 \times \hat{\sigma}_{y}$ from 0 , implying that the probability of a positive scaling ratio is small. Precipitation is expected to decrease in summer in all CSRs. Although $\hat{\sigma}_{y}$ is relatively large for summer, the mean scaling ratio differs about $2 \times \hat{\sigma}_{y}$ from zero. The mean scaling ratio is positive in winter. With the exception of Iberia, the probability is small that YMP takes negative values for that season. The contribution of natural variability to the total variance $\sigma_{y}^{2}$ for precipitation is much larger than that for temperature. In winter and autumn $\sigma_{e}^{2}$ is the largest variance component for all CSRs. In a number of cases, no positive estimate of $\sigma_{a}^{2}$ and $\sigma_{b}^{2}$ was found, partly due to the large influence of natural variability on the scaling ratio and, for $\sigma_{a}^{2}$ also, to the small number of AOGCMs in the PRUDENCE project. For the summer season, there is a considerable contribution of $\sigma_{b}^{2}$ to $\sigma_{y}^{2}$ for the Rhine basin and the Swiss CSRs; the component $\sigma_{b}^{2}$ is of minor 
importance for the other seasons. A rather strong correlation was obtained for the $e_{i j}$ of the HadCM3-A2 cluster. The largest values of $\rho_{e, 1}$ are found in the winter season and the smallest values in the summer season.

\section{Seasonal variation of the range of the scaling ratios}

Figure 5 shows that the range of the scaling ratio is usually much higher for summer than for the other seasons. This is mainly because the inter-RCM variance $\sigma_{b}^{2}$ is quite significant in summer. In winter, meteorological events are largely determined by large-scale circulation patterns, which are mostly accounted for by the driving AOGCMs. The variation in the scaling ratio is then due to systematic differences between the simulated large-scale patterns of these models (represented by the $a_{i}$ in the ANOVA model) and natural variability. In summer, small -scale processes are also important (formation of convective rainfall cells, evolution of soil moisture and evapotranspiration). These processes are accounted for mainly by the RCMs. Their description has, however, to be simplified because of their complexity and because of the large size of RCM grid boxes. The parameterisation of these processes may differ significantly from one RCM to the other. Inter-model difference results then from differences between the driving AOGCM and between RCM parameterisations (Christoph Frei, pers. comm.). Results obtained for summer are, thus, expected to be more variable from one RCM to another in comparison with results for winter.

\section{Simulating Probability Density Functions of seasonal regional changes}

For each SWURVE CSR, the Probability Density Function of regional change is next obtained via Monte Carlo simulation as indicated in the introduction. A global mean warming value $\Delta T$ is generated from a log-normal approximation to the Wigley and Raper (2001) distribution. This value is then combined with a random scaling ratio $y$ to obtain one realisation $x=y \Delta T$ of the regional change $X$. It is assumed that $y=\mu+a+b+e$, where $a, b$ and $e$ are independent normal random variables with mean 0 and variances $\sigma_{a}^{2}, \sigma_{b}^{2}$ and $\sigma_{N}^{2} /(\Delta T)^{2}$, respectively. The regional change $X$ can then be represented as a simple function of three independent random variables:

$$
X=\tilde{Y} . \Delta T+N
$$

where $\tilde{Y}$ is a normal random variable with mean $\mu$ and variance $\sigma_{a}^{2}+\sigma_{b}^{2}$, and $N$, the contribution of natural variability, is normal with mean 0 and variance $\sigma_{N}^{2}$.

Table 6 presents the percentiles of the resulting distributions. Probability Density Functions of the seasonal changes are shown in Fig. 6. The differences between CSRs and seasons follow from the properties of the scaling ratios as discussed earlier in the analysis of ANOVA results. Some additional comments have, however, to be noted.

\section{ANNUAL TEMPERATURE CHANGES}

All percentiles of the annual temperature change for NWE in Table 6 are smaller than the corresponding percentiles for the other CSRs. For NWE the range between the 5th and 95 th percentile is $3.1{ }^{\circ} \mathrm{C}$, which is $20 \%$ larger than that for the Wigley and Raper (2001) distribution of the global mean temperature change. The percentiles for the Rhine basin, Iberia and the Swiss CSRs bear a strong resemblance (the 1st, 5th, 50th, 95th and 99th percentiles are about 1.3, $1.8,3.3,6$ and $7.6^{\circ} \mathrm{C}$ ) as a result of the similarity between the means and variances of the underlying scaling ratios. The range between the 95 th and 5 th percentile, about $4.2^{\circ} \mathrm{C}$ for these CSRs, is considerably larger than that for the NWE CSR (and 60\% larger than that for the Wigley and Raper (2001) distribution of global mean warming). This difference can be explained easily by examining the expression for the variance of $X$. Since $\tilde{Y}, \Delta T$ and $N$ are independent, the variance of $X$ is given by

$$
\begin{array}{r}
\operatorname{var} X=\left(\sigma_{a}^{2}+\sigma_{b}^{2}\right) \cdot \operatorname{var} \Delta T+\mu^{2} \cdot \operatorname{var} \Delta T+ \\
\left(\sigma_{a}^{2}+\sigma_{b}^{2}\right) \cdot[\mathrm{E}(\Delta T)]^{2}+\sigma_{N}^{2}
\end{array}
$$

For the annual temperature change of the CSRs being considered, the second term on the right-hand side dominates strongly. For the NWE CSR, this term is smaller than for the other CSRs because of the smaller value of $\mu$ for NWE (Table 5).

\section{ANNUAL PRECIPITATION CHANGES}

For Iberia, only the 99th percentile is slightly positive whereas the lower percentiles are negative, suggesting a decrease in annual precipitation. The direction of change is more uncertain for the other CSRs. There is a good correspondence between the percentiles for the Rhine basin and the two Swiss CSRs (the 1st, 50th and 99th percentiles are about $-20,-5$ and $5 \%$ ).

\section{SEASONAL TEMPERATURE CHANGES}

For all CSRs, the expected warming for summer is higher with a larger uncertainty range than the regional warming for the other seasons (Table 6). With the exception of NWE, 
Table 6. 99th, 95th, 50th, 20th, 5th and 1st percentiles of regional temperature and precipitation changes $(X M T$ and $X M P)$ obtained from Monte Carlo simulations for the five SWURVE CSRs (percentiles based on 50000 simulations from a log-normal approximation to the Probability Density Function of the global mean warming from Wigley and Raper (2001) and from the Probability Density Functions of the scaling variables derived from the 19 PRUDENCE RCM experiments). The minimum and maximum changes in the 19 RCM experiments are also given for comparison.

\begin{tabular}{|c|c|c|c|c|c|c|c|c|c|c|c|}
\hline & & \multicolumn{5}{|c|}{ Absolute Temperature changes $\left({ }^{\circ} \mathrm{C}\right)$} & \multicolumn{5}{|c|}{ Relative Precipitation changes (\%) } \\
\hline & & Annual & $D J F$ & $M A M$ & $J J A$ & $S O N$ & Annual & $D J F$ & $M A M$ & $J J A$ & $S O N$ \\
\hline \multirow[t]{8}{*}{ NWE } & 99th & 5.4 & 4.7 & 5.2 & 6.2 & 5.9 & 17 & 47 & 19 & 5 & 27 \\
\hline & 95th & 4.2 & 3.5 & 4 & 4.9 & 4.7 & 12 & 37 & 14 & -2 & 20 \\
\hline & 50 th & 2.3 & 1.8 & 2 & 2.7 & 2.7 & 3 & 18 & 2 & -19 & 6 \\
\hline & 20th & 1.6 & 1.1 & 1.3 & 1.9 & 2 & -1 & 10 & -5 & -30 & -1 \\
\hline & 05 th & 1.1 & 0.7 & 0.8 & 1.4 & 1.5 & -6 & 3 & -10 & -43 & -7 \\
\hline & $01 \mathrm{st}$ & 0.8 & 0.3 & 0.4 & 1 & 1.1 & -9 & -3 & -16 & -57 & -13 \\
\hline & Max RCMs & 4 & 3.4 & 4 & 4.6 & 4.2 & 14 & 38 & 18 & -4 & 17 \\
\hline & Min RCMs & 1.6 & 1 & 1.1 & 1.8 & 1.7 & -7 & 7 & -11 & -42 & -9 \\
\hline \multirow[t]{8}{*}{ RH } & 99th & 7.4 & 6.5 & 6.4 & 10 & 7.3 & 6 & 36 & 16 & 6 & 9 \\
\hline & 95 th & 5.8 & 5.1 & 5 & 7.8 & 5.8 & 3 & 29 & 10 & -2 & 5 \\
\hline & 50th & 3.2 & 2.7 & 2.6 & 4.1 & 3.4 & -4 & 14 & -3 & -21 & -5 \\
\hline & 20th & 2.3 & 1.9 & 1.8 & 2.8 & 2.5 & -7 & 7 & -9 & -33 & -10 \\
\hline & 05 th & 1.7 & 1.2 & 1.2 & 1.9 & 1.9 & -11 & 0 & -16 & -48 & -16 \\
\hline & $01 \mathrm{st}$ & 1.2 & 0.7 & 0.7 & 1.2 & 1.4 & -15 & -5 & -23 & -64 & -21 \\
\hline & Max RCMs & 6 & 5 & 5.4 & 8.3 & 5.7 & 5 & 36 & 10 & 10 & 6 \\
\hline & Min RCMs & 2.2 & 1.8 & 1.7 & 2.2 & 2.5 & -11 & -1 & -17 & -52 & -20 \\
\hline \multirow[t]{8}{*}{ IB } & 99th & 7.4 & 5.7 & 7.4 & 9.8 & 7.5 & 2 & 39 & -1 & 9 & 1 \\
\hline & 95 th & 6 & 4.5 & 5.9 & 7.9 & 6 & -4 & 28 & -9 & -3 & -6 \\
\hline & 50th & 3.4 & 2.5 & 3.3 & 4.6 & 3.5 & -18 & 3 & -31 & -33 & -23 \\
\hline & 20th & 2.6 & 1.8 & 2.3 & 3.5 & 2.6 & -26 & -10 & -44 & -51 & -33 \\
\hline & 05th & 1.9 & 1.3 & 1.6 & 2.6 & 1.9 & -34 & -22 & -58 & -72 & -43 \\
\hline & $01 \mathrm{st}$ & 1.5 & 0.9 & 1.1 & 2 & 1.4 & -42 & -32 & -71 & -89 & -53 \\
\hline & Max RCMs & 6 & 4.1 & 6.4 & 7.7 & 5.8 & -8 & 22 & -18 & -2 & -3 \\
\hline & Min RCMs & 2.6 & 1.7 & 2 & 3.2 & 2.6 & -35 & -19 & -62 & -83 & -46 \\
\hline \multirow[t]{8}{*}{ JL } & 99th & 7.6 & 6.7 & 7 & 11 & 7.4 & 6 & 32 & 18 & 3 & 6 \\
\hline & 95th & 6.1 & 5.2 & 5.4 & 8.3 & 5.9 & 2 & 25 & 11 & -4 & 2 \\
\hline & 50 th & 3.3 & 2.8 & 2.8 & 4.5 & 3.4 & -6 & 10 & -5 & -24 & -9 \\
\hline & 20th & 2.4 & 1.9 & 1.9 & 3.2 & 2.5 & -11 & 3 & -13 & -37 & -14 \\
\hline & 05 th & 1.8 & 1.3 & 1.2 & 2.2 & 1.9 & -16 & -4 & -22 & -52 & -19 \\
\hline & $01 \mathrm{st}$ & 1.3 & 0.8 & 0.8 & 1.5 & 1.4 & -22 & -10 & -31 & -68 & -24 \\
\hline & Max RCMs & 6.3 & 5 & 5.9 & 8.9 & 5.9 & 1 & 41 & 11 & -3 & 2 \\
\hline & Min RCMs & 2.3 & 1.8 & 1.7 & 2.8 & 2 & -19 & 2 & -27 & -55 & -20 \\
\hline \multirow[t]{8}{*}{ MA } & 99th & 7.7 & 6.9 & 7.3 & 10 & 7.5 & 6 & 32 & 17 & 5 & 6 \\
\hline & 95 th & 6.1 & 5.4 & 5.7 & 8.1 & 6 & 2 & 25 & 10 & -3 & 1 \\
\hline & 50 th & 3.4 & 2.9 & 3 & 4.5 & 3.4 & -7 & 9 & -6 & -23 & -9 \\
\hline & 20th & 2.5 & 2 & 2.1 & 3.2 & 2.5 & -12 & 1 & -15 & -36 & -15 \\
\hline & 05 th & 1.8 & 1.3 & 1.3 & 2.4 & 1.9 & -18 & -6 & -25 & -52 & -20 \\
\hline & $01 \mathrm{st}$ & 1.4 & 0.8 & 0.8 & 1.7 & 1.4 & -24 & -13 & -35 & -69 & -25 \\
\hline & Max RCMs & 6.2 & 5.2 & 6.1 & 8.3 & 5.9 & 0 & 39 & 12 & 6 & 2 \\
\hline & Min RCMs & 2.4 & 1.9 & 1.8 & 2.7 & 2.4 & -21 & 0 & -29 & -54 & -17 \\
\hline
\end{tabular}

the 99th percentile of the summer warming is as large as $10^{\circ} \mathrm{C}$. Figure 6 shows that the Probability Density Function for spring resembles either the Probability Density Function for winter (NWE, Rhine basin and Swiss CSRs) or autumn (Iberia). 


\section{SEASONAL PRECIPITATION CHANGES}

In the discussion of the ANOVA results it was already noted that precipitation is expected to decrease in summer for all CSRs. The decrease in precipitation is accompanied by a negatively skewed PDF of the relative changes (Fig. 6), implying that quite large decreases are possible. Table 6 shows that the $1 \mathrm{st}$ percentile of the relative change is as low as $-57 \%$ for NWE, $-64 \%$ for the Rhine basin, $-68 \%$ for the Swiss CSRs, and even $-89 \%$ for Iberia. For winter, the Probability Density Function is more or less centred on the origin for Iberia (indicating that an increase in precipitation is as likely as a decrease) but for the other CSRs the 20th and higher percentiles are positive (indicating that a precipitation increase is probable). The expected increase for the latter is accompanied by a positively skewed Probability Density Function of the relative changes, which can be as high as $47 \%$ (99th percentile for NWE). For spring, all percentiles of the relative changes are negative for Iberia whereas the Probability Density Functions are more or less centred on the origin for the other CSRs. The latter is also the case for NWE for autumn. For the other CSRs most percentiles are negative for autumn, indicating that a decrease in precipitation is more likely than an increase.

\section{PERCENTILES OF REGIONAL CHANGES IN THIS STUDY VERSUS THOSE OBTAINED FROM THE PRUDENCE EXPERIMENTS}

Table 6 shows that for all CSRs, the maximum regional changes from the 19 RCM experiments correspond more or less to the 95th percentiles of the regional changes from the Monte Carlo simulations in this study. This holds both for the temperature and precipitation changes and for the annual and seasonal changes. The minimum changes from the RCMs correspond to the 20th percentiles of the simulated values for $X M T$ and to the 5th percentiles of the simulated values for $X M P$. To assess climate-change impacts on specific water systems, regional scenarios from RCM experiments only would, thus, not be representative enough of the temperature changes. This is mainly due to the fact that the lowest and highest global mean warming in the PRUDENCE AOGCM experiments correspond to the 40th and 85 th percentile of the 1990 to 2070-2100 global mean warming distribution derived from Wigley and Raper (2001). The PRUDENCE experiments are, thus, unable to capture the low regional warming that would be obtained for low global mean warming. The estimation of regional temperature changes therefore needs a relevant Probability Density Function of global mean warming. By contrast, the regional precipitation changes from the PRUDENCE experiments cover more or less the full range of possible precipitation changes as predicted by the Monte Carlo simulations in this study. For regional precipitation the uncertainty of the regional scaling relationship has a larger influence on the distribution of the relative changes than for temperature. That the minimum regional changes in the 19 RCM experiments correspond to the 5th percentile and the maximum to the 95 th percentile is a result to be expected for a sample of 19 independent realisations. This suggests that the dependencies between the various RCM simulations have little effect on the range of regional climate change. It should finally be noted that the Probability Density Function is sensitive to the values of $\mu$ and $\sigma_{y}^{2}$, and not to the partition of $\sigma_{y}^{2}$ over the variance components $\sigma_{a}^{2}, \sigma_{b}^{2}$ and $\sigma_{e}^{2}$.

\section{Conclusion}

The uncertainty of regional climate changes can be estimated with different AOGCM-RCM experiments for different emission scenarios. Unfortunately, such experiments are highly time consuming and cannot be applied to assess regional changes for all possible emission scenarios and all possible sets of uncertain model parameters. The methodology presented in the paper allows the generation of an extended range of possible regional changes for both seasonal temperatures and precipitation. It combines a Probability Density Function of the global mean warming derived from those of Wigley and Raper (2001) with the Probability Density Functions of scaling ratios from a large set of RCM experiments carried out in the framework of the PRUDENCE project (Christensen et al., 2002). The resulting Probability Density Functions of regional changes can be used to produce a large number of climate change scenarios as needed for impact studies.

The Probability Density Functions of scaling ratios are based on an analysis of the relationships between regional changes and global mean warming. Results indicate that a linear relationship between these regional-global changes can be assumed as a first approximation. The emission scenario and the driving model are usually expected to give a large contribution to the uncertainty in regional climate change. Unfortunately, this contribution could not be estimated accurately because only three AOGCMs and two emission scenarios were considered in the PRUDENCE project. For precipitation, the estimation of the uncertainty due to the driving 'emission-scenario AOGCM' configuration was further hampered by the large natural variability of the seasonal and annual mean values. In a number of cases, RCM inter-model differences contributed substantially to the total variance of the scaling ratio. Most of these cases were found in summer and autumn for 
Probability distributions for regional climate change from uncertain global mean warming and uncertain scaling relationship
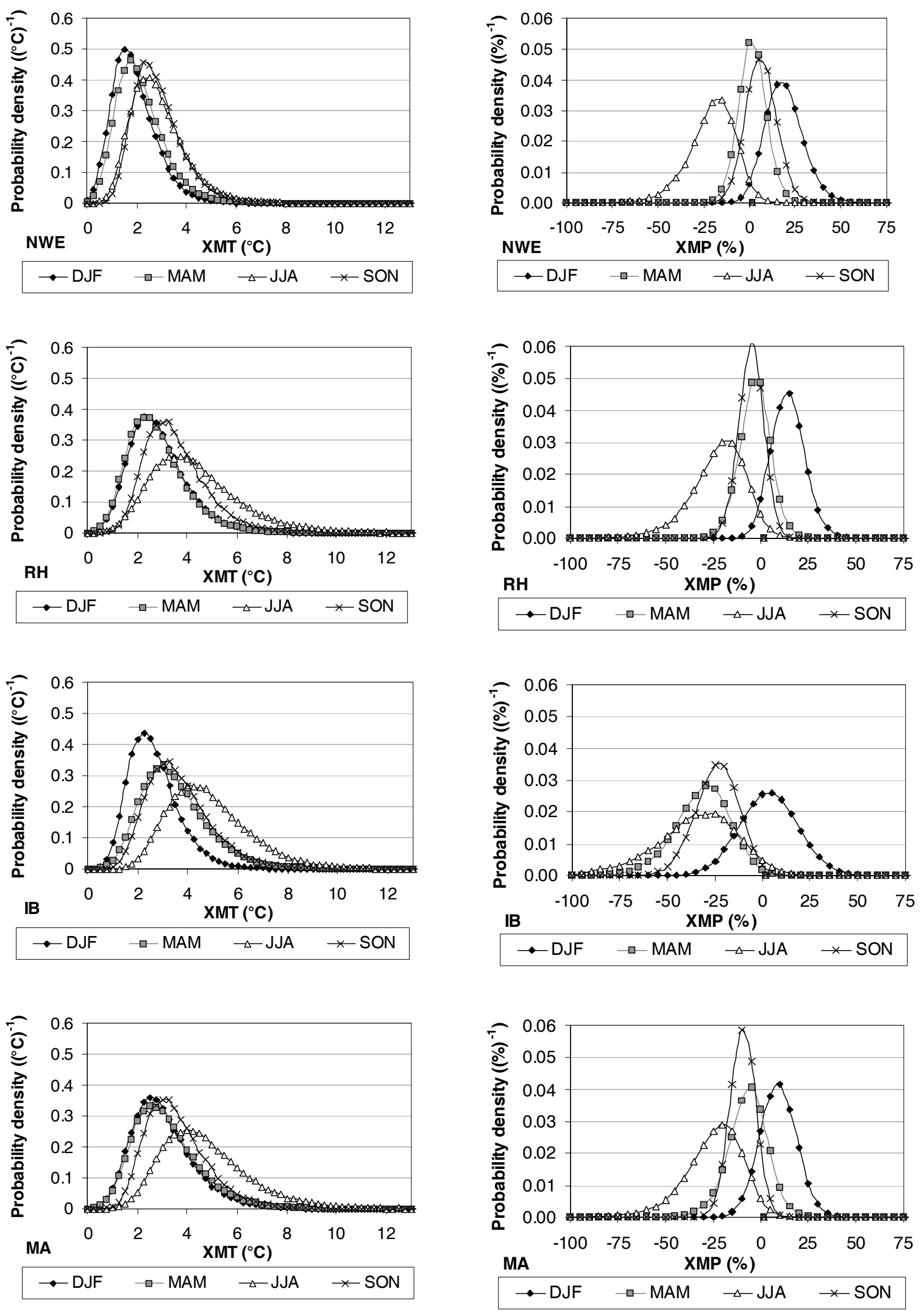

Fig. 6. Probability Density Functions of regional changes for (a) seasonal temperatures and (b) seasonal precipitation for four SWURVE CSRs (the Probability Density Functions for the Jura lakes CSR are not shown because they resemble those for the other Swiss CSR (MA)). The Probability Density Functions are based on 50000 Monte Carlo simulations. Left: absolute temperature change $\left(X M T\right.$ in $\left.{ }^{\circ} \mathrm{C}\right) ;$ right: relative precipitation change (XMP in \%). 
temperature and in summer for precipitation. Natural variability turned out to be an important source of uncertainty for the scaling ratio for precipitation, but not for temperature.

For the five SWURVE CSRs, the ranges of the changes in temperature (resp. precipitation) from the Monte Carlo simulations are larger than (resp. similar to) those obtained from the 19 PRUDENCE RCM experiments. For temperature, this has to be related mainly to the rather high sensitivity to radiative forcing of the AOGCMs considered in this study. The range of the regional precipitation changes depends strongly on the uncertainty of the scaling ratio. Two companion papers of this special Hydrology and Earth System Sciences issue focusing on the two Swiss SWURVE CSRs reveal that uncertainty associated with scaling explains much of the total uncertainty in impact Probability Density Functions (Schaefli et al., 2007; Hingray et al., 2007). This is also in line with results obtained for different hydroclimatic regions of Switzerland by Horton et al. (2006).

The design of the PRUDENCE ensemble is far from optimal from an ANOVA point of view (small number of AOGCMs, very uneven distribution of RCM experiments over the AOGCM simulations). The estimates of $\sigma_{a}^{2}$ and $\sigma_{b}^{2}$ were based on two sums of squares. Other quadratic forms of the $y_{i j}$ may be considered (Searle, 1997). The ANOVA model given in Eqn. (3) assumes that the effects of the 'emission-scenario AOGCM' configuration and the $\mathrm{RCM}$ are purely additive. There is some need to investigate this assumption. A reviewer suggested the development of separate ANOVA models for the future and control climate. Natural variability may be included as a between-year component in these models.

The results of this work are of course highly conditioned on the different hypotheses and simplifications used to obtain the global warming Probability Density Function and the Probability Density Functions of scaling ratios. Global warming and scaling ratios were assumed, respectively, to be log-normally and normally distributed. By contrast, Jones (2000) advocates the use of the uniform distribution to describe the uncertainty of global warming and scaling ratios; in his study, the lower and upper bound of the distribution were set equal to the minimum and maximum values in a suite of climate model experiments. The two methods were compared by Ekström et al. (2007) for the changes in annual temperature and precipitation in the five SWURVE CSRs. The directions of change are similar in both methods but the magnitude of the expected changes differs. The global warming Probability Density Function depends on assumptions regarding future greenhouse gas emissions. Wigley and Raper (2001) arbitrarily assumed that each of the 35 SRES scenarios was equally likely. An alternative approach that avoids assumptions about the likelihood of emission scenarios is to construct separate climate-change Probability Density Functions for a number of these emission scenarios. The climate sensitivity is another uncertain factor that determines the global warming Probability Density Function. Wigley and Raper (2001) assumed that the climate sensitivity ranged between 1.5 and $4.5^{\circ} \mathrm{C}$ with a probability of $90 \%$. Some authors (Andronova and Schlesinger, 2001; Stainforth et al., 2005) have reported much wider intervals (up to about $9^{\circ} \mathrm{C}$ ).

The possibility of a climatic surprise is not accounted for in the climate-change Probability Density Functions. Probability Density Functions of regional changes describe only uncertainty resulting from known sources of uncertainty that can be represented by appropriate Probability Density Functions.

To assess climate change impacts on water related activities, the changes in means for key variables such as temperature and precipitation are of major importance but are, however, not sufficient. Impacts are usually highly dependent on extreme events. As extremes are highly sensitive to the width of statistical distributions, changes in variability are often said to be more important than changes in averages (Katz and Brown, 1992; Schaer et al., 2004). Changes in variability are also outcomes of climate model experiments and, as already shown by Räisänen (2002), changes in variability may differ from one experiment to another. Uncertainty in the change in variability can be accounted for with the same methodology as that presented here. To assess climate change impacts on water related activities, the way such uncertainties can be combined to produce time series scenarios of temperature and precipitation for future climate conditions has finally to be addressed (at a daily time step, for example). One difficulty is to account for the possible correlation between the changes in the different key meteorological variables in this scenario development. High correlation is, for example, usually predicted between the four mean seasonal temperature changes. This is, of course, partly due to the fact that these changes are strongly coupled to the global mean warming. It is, however, also due to the high correlation between seasonal scaling ratios obtained from climate-change experiments. A possible framework to account for such correlations is proposed in Hingray et al. (2007).

\section{Acknowledgements}

The authors record their gratitude to the PRUDENCE (Prediction of Regional scenarios and Uncertainties for Defining EuropeaN Climate change risks and Effects) 
project members for allowing the use of the seasonal RCM output on which this paper is based. This paper benefited also from the support of different scientists. The following researchers are especially acknowledged: Ole Christensen for establishing the PRUDENCE Data Server and providing the seasonal maps of temperature and precipitation, Pier Luigi Vidale for providing CHRM data from the ETHZ DoDs Model Data Server, Tom Wigley for providing global mean warming Probability Density Functions, Marie Ekström for providing post-processed data from the PRUDENCE web site, Jean Marie Helbling and Christoph Frei for helping to develop this methodology. Two anonymous reviewers are also thanked for their comments on an earlier version of the paper. This work is part of the 2001-2004 EU project SWURVE (Sustainable Water: Uncertainty, Risk and Vulnerability estimation in Europe), funded under the EU Energy, Environment and Sustainable Development programme, grant number EVK1-200000075 .

\section{References}

Andronova, N.G. and Schlesinger, M.E., 2001. Objective estimation of the probability density function for climate sensitivity. J. Geophys. Res., 106 (D19), 22,605-22,611.

Arnell, N.W. and Hulme, M., 2000. Implications of Climate Changes for large dams and their management. Thematic Review II.2 prepared as an input to the World Commission on Dams, Cape Town, RSA. www.dams.org.

Arribas, A., Gallardo, C., Gaertner, M.A. and Castro, M., 2003. Sensitivity of the Iberian Peninsula climate to a land degradation. Clim. Dynam., 20, 477-489.

Christensen, J.H., Carter, T.R. and Giorgi, F., 2002. PRUDENCE employs new methods to assess European Climate Change. EOS, AGU, 83, 147.

Christensen, J.H., Räisänen, J., Iversen, T., Bjørge, D., Christensen, O.B. and Rummukainen, M., 2001. A synthesis of regional climate change simulations - A Scandinavian perspective. Geophys. Res. Lett., 28, 1003-1006.

Doms, G. and Schättler, U., 1999. The Nonhydrostatic LimitedArea Model LM (Lokal-Modell) of DWD, Part I: Scientific Documentation. Deutscher Wetterdienst, Geschäftsbereich Forschung und Entwicklung.

Ekström, M., Hingray, B., Mezghani, A. and Jones, P.D., 2007. Regional climate model data used within the SWURVE project 2: addressing uncertainty in regional climate model data for five European case study areas. Hydrol. Earth Syst. Sci., 11, 1085-1096.

Frei, C., Christensen, J.H., Deque, M., Jacob, D., Jones, R.G. and Vidale, P.L., 2003. Daily precipitation statistics in regional climate models: Evaluation and intercomparison for the European Alps. J. Geophys. Res., 108 (D3), 4124, doi:10.1029/ 2002JD002287.

Gibelin, A.L. and Déqué, M., 2003. Anthropogenic climate change over the Mediterranean region simulated by a global variable resolution model. Clim. Dynam., 20, 327-339.

Giorgi, F. and Mearns, L., 2002. Calculation of average, uncertainty range, and reliability of regional climate changes from AOGCM simulations via the "Reliability Ensemble Averaging (REA) Method". J. Climate, 15, 1141-1158.
Giorgi, F., Marinucci, M.R. and Bates, G.T., 1993a. Development of a second generation regional climate model (REGCM2). Part $\mathrm{I}$ : Boundary layer and radiative transfer processes. Mon. Weather Rev., 121, 2794-2813.

Giorgi, F., Marinucci, M.R., Bates, G.T. and DeCanio, G., 1993 b. Development of a second generation regional climate model (REGCM2). Part II: Convective processes and assimilation of lateral boundary conditions. Mon. Weather Rev., 121, 28142832.

Gordon, C., Cooper, C., Senior, C.A., Banks, H., Gregory, J.M., Johns, T.C., Mitchell, J.F.B. and Wood, R.A., 2000. The simulation of SST, sea ice extents and ocean heat transports in a version of the Hadley Centre coupled model without flux adjustments. Clim. Dynam., 16, 147-168.

Hingray, B., Mouhous, N., Mezghani, A., Bogner, K., Schaefli, B. and Musy, A., 2007. Accounting for global warming and scaling uncertainties in climate change impact studies: application to a regulated lakes system. Hydrol. Earth Syst. Sci., 11. 1207-1226.

Horton, P., Schaefli, B., Mezghani, A., Hingray, B. and Musy. A., 2006. Assessment of climate change impacts on Alpine discharge regimes with climate model uncertainty. Hydrol. Process., 20, 2091-2109.

Hulme, M., Jenkins, G.J., Lu, X., Turnpenny, J.R., Mitchell, T.D., Jones, R.G., Lowe, J., Murphy, J.M., Hassell, D., Boorman, P., McDonald, R. and Hill, S., 2002. Climate Change Scenarios for the United Kingdom: The UKCIP02 Scientific Report. Tyndall Centre for Climate Change Research, School of Environmental Sciences, University of East Anglia, Norwich, UK. 112pp.

IPCC, 2001. Climate Change 2001: The Scientific Basis. Contribution of Working Group I to the Third Assessment Report of the Intergovernmental Panel on Climate Change, J.T. Houghton, Y. Ding, D.J. Griggs, M. Noguer, P.J. van der Linden, X. Dai, K. Maskell, and C.A. Johnson, (Eds). Cambridge University Press, Cambridge UK. 881pp.

Jacob, D., 2001. A note to the simulation of the annual and interannual variability of the water budget over the Baltic Sea drainage basin. Meteorol. Atmos. Phys., 77, 61-73.

Jones, R.N., 2000. Analysing the risk of climate change using an irrigation demand model. Climate Res., 14, 89-100.

Katz, R.W. and Brown, B.G., 1992. Extreme events in a changing climate: variability is more important than averages. Climatic Change, 21, 289-302.

Kilsby, C.G., 2007. SWURVE: Sustainable Water: Uncertainty Risk and Vulnerability in Europe. Hydrol. Earth Syst. Sci., 11, 1065-1068.

Lenderink, G., van den Hurk, B., van Meijgaard, E., van Ulden, A. and Cuijpers, H., 2003. Simulation of present-day climate in RACMO2: first results and model developments. KNMI Technical Report TR 252. 24pp.

Nakicenovic, N. and Swart, R., Eds 2000. Special Report on Emissions Scenarios. Cambridge University Press, Cambridge, UK.

Pope, V.D., Gallani, M.L., Rowntree, P.R. and Stratton, R.A., 2000. The impact of new physical parameterizations in the Hadley Centre climate model - HadAM3. Clim. Dynam., 16, 123-146.

Räisänen, J., 2001. CO2-induced climate change in CMIP2 experiments: Quantification of agreement and role of internal variability. J. Climate, 14, 2088-2104.

Räisänen, J., 2002. CO2-induced changes in interannual temperature and precipitation variability in 19 CMIP2 experiments. J. Climate, 15, 2395-2411.

Räisänen, J., Hansson, U., Ullerstig, A., Döscher, R., Graham, L.P., Jones, C., Meier, H.E.M., Samuelsson, P. and Willén, U., 2004. European climate in the late 21 st century: regional 
simulations with two driving global models and two forcing scenarios. Clim. Dynam., 22, 13-31.

Roeckner, E., Bengtsson, L., Feichter, J., Lelieveld, J. and Rodhe, H., 1999. Transient climate change simulations with a coupled atmosphere-ocean GCM including the tropospheric sulfur cycle. J. Climate., 12, 3004-3032.

Royer, J.F., Cariolle, D., Chauvin, F., Déqué, M., Douville, H., Hua, R.M., Planton, S., Rascol, A., Ricard, J.L., Salas y Melia, D., Sevault, F., Simon, P., Somot, S., Tyteca, S., Terray, L. and Valcke, S., 2002. Simulation of climate changes during the $21 \mathrm{st}$ century including stratospheric ozone. CR Geosci., 334, 147154.

Schaefli, B., Hingray, B. and Musy, A., 2007. Climate change and hydropower production in the Swiss Alps: quantification of potential impacts and related modelling uncertainties. Hydrol. Earth Syst. Sci., 11, 1191-1205.

Schaer, C., Vidale, P.L., Luthi, D., Frei, C., Haberli, C., Liniger, M.A. and Appenzeller, C., 2004. The role of increasing temperature variability in European summer heatwaves. Nature, 427, 332-336.

Searle, S.R., 1997. Linear Models. Wiley, New York, USA.

Stainforth, D.A., Alna, T., Christensen, C., Collins, M., Fauli, N., Frame, D.J., Kettleborough, J.A., Knight, S., Martin, A., Murphy, J.M., Piani, C., Sexton, D., Smith, L.A., Spicer, R.A., Thorpe, A.J. and Allen, M.R., 2005. Uncertainty in predictions of the climate response to rising levels of greenhouse gases. Nature, 433, 403-406.

Stuart, A. and Ord, J.K., 1987. Kendall's Advanced Theory of Statistics, Vol. 1: Distribution Theory, 5th edition. Charles Griffin, London, UK.

Vidale, P.L., Lüthi, D., Frei, C., Seneviratne, S. and Schär, C., 2003. Predictability and uncertainty in a Regional Climate Model. J. Geophys. Res., 108 (D18), 4586, doi: 10.1029/ 2002JD002810.

Whetton, P.H., Haylock, M.R. and Galloway, R., 1996. Climate change and snow-cover duration in the Australian Alps. Climatic Change, 32, 447-479.

Wigley, T.M.L. and Raper, S.C.B., 2001. Interpretation of high projections for global-mean warming. Science, 293, 451-454.

\section{Appendix A: Natural variability}

The effect of natural variability is included in the ANOVA model (3) by the term $e_{i j}$. Common GCM boundaries lead to a correlation between the $e_{i j}$ from RCM experiments within the same AOGCM cluster. Expressions for the correlation coefficients and the variances of the $e_{i j}$ are derived in this appendix, first for temperature and then for precipitation.

Two different RCMs, $\mathrm{RCM}_{p}$ and $\mathrm{RCM}_{q}$, are considered, for which the changes in mean temperature are given by

$$
\begin{aligned}
& X M T_{p}=M T_{\text {future }, p}-M T_{\text {control }, p} \\
& X M T_{q}=M T_{\text {future }, q}-M T_{\text {control }, q}
\end{aligned}
$$

It is expected that there is no correlation between the means in the control and future climate. There might, however, be a correlation $\rho_{C}$ between $M T_{\text {control, },}$ and $M T_{\text {control, },}$ and a correlation $\rho_{F}$ between $M T_{\text {future }, p}$ and $M T_{\text {future }, q}$. Then it follows:

$$
\begin{aligned}
& \operatorname{var}\left(X M T_{k}\right)=\sigma_{F, k}^{2}+\sigma_{C, k}^{2} \\
& \operatorname{cov}\left(X M T_{p}, X M T_{q}\right)=\rho_{F} \sigma_{F, p} \sigma_{F, q}+\rho_{C} \sigma_{C, p} \sigma_{C, q}
\end{aligned}
$$

with $\sigma_{C, k}=\operatorname{stdev}\left(M T_{\text {control }, k}\right)$ and $\sigma_{F, k}=\operatorname{stdev}\left(M T_{\text {future }, k}\right)$, $k=p, q$.

From Eqns. (A3) and (A4), the correlation between $X M T_{p}$ and $X M T_{q}$ is:

$$
\rho_{X M T}=\frac{\rho_{F} \sigma_{F, p} \sigma_{F, q}+\rho_{C} \sigma_{C, p} \sigma_{C, q}}{\sqrt{\left(\sigma_{F, p}^{2}+\sigma_{C, p}^{2}\right)\left(\sigma_{F, q}^{2}+\sigma_{C, q}^{2}\right)}}
$$

Assuming independence between years, the standard deviations $\sigma_{C, k}$ and $\sigma_{F, k}$ are obtained as

$$
\begin{gathered}
\sigma_{C, k}=\sigma_{\text {control }, k} / \sqrt{n_{\text {control }}} \quad, k=p, q \\
\sigma_{F, k}=\sigma_{\text {future }, k} / \sqrt{n_{\text {future }}} \quad, k=p, q
\end{gathered}
$$

where $\sigma_{\text {control, } k}$ and $\sigma_{\text {future, } k}$ are the standard deviations of the individual seasonal (resp. annual) values, and $n_{\text {control }}$ and $n_{\text {future }}$ are the number of years in the control and future run $\left(n_{\text {control }}\right.$ $=n_{\text {future }}=30$ ). No attempts were made to account for serial dependence effects, which would require long control simulations. Hence, the natural variability of XMT might be somewhat underestimated. The assumption of independence between years further implies that $\rho_{F}$ and $\rho_{C}$ are equal to the correlation coefficients of the individual seasonal (resp. annual) values.

A linear trend was subtracted from the simulated seasonal (resp. annual) values in the future run before estimation of $\sigma_{\text {future, } k}^{2}$ and $\rho_{F}$. A pooled estimate of $\sigma_{N}^{2}=\operatorname{var}(X M T)$ was obtained by averaging the individual estimates from the 12 RCM experiments starred in Table 2.

Because the variability of the global mean temperature is small compared to that of the seasonal temperatures in the case study regions, $\Delta T$ in Eqn. (1) may be considered as a constant. Hence,

$$
\operatorname{var}(Y M T) \approx \operatorname{var}(X M T) /(\Delta T)^{2}
$$

and

$$
\operatorname{corr}\left(Y M T_{p}, Y M T_{q}\right) \approx \rho_{X M T}
$$

The variance $\sigma_{e, i}^{2}$ for the $i$ th 'emission-scenario AOGCM' cluster was obtained by dividing the pooled estimate of $\sigma_{N}^{2}$ 
by the square of the global temperature change $\Delta T_{i}$. The correlation coefficient $\rho_{e, i}$ was set equal to the cluster mean of the estimates of $\rho_{X M T}$.

Similar expressions can be derived for the variances and correlations of the changes XMP in mean precipitation. Let

$$
\begin{gathered}
X M P_{p}=M P_{\text {future }, p} / M P_{\text {control }, p}-1 \\
X M P_{q}=M P_{\text {future }, q} / M P_{\text {control }, q}-1
\end{gathered}
$$

Define $\mu_{C, k}=\mathrm{E}\left(M P_{\text {control }, k}\right), \mu_{F, k}=\mathrm{E}\left(M P_{\text {future, } k}\right), k=p, q$. Approximations to var $\left(X M P_{k}\right)$ and the covariance between $X M P_{p}$ and $X M P_{q}$ can be obtained by the delta method (Stuart and Ord, 1987, Sections 10.5 and 10.6):

$$
\begin{gathered}
\operatorname{var}\left(X M P_{k}\right) \approx \frac{\mu_{F, k}^{2}}{\mu_{C, k}^{2}}\left[\frac{\sigma_{F, k}^{2}}{\mu_{F, k}^{2}}+\frac{\sigma_{C, k}^{2}}{\mu_{C, k}^{2}}\right], k=p, q \\
\operatorname{cov}\left(X M P_{p}, X M P_{q}\right) \approx \\
\frac{\mu_{F, p}}{\mu_{C, p}} \cdot \frac{\mu_{F, q}}{\mu_{C, q}} \cdot\left[\rho_{F} \frac{\sigma_{F, p}}{\mu_{F, p}} \frac{\sigma_{F, q}}{\mu_{F, q}}+\rho_{C} \frac{\sigma_{C, p}}{\mu_{C, p}} \frac{\sigma_{C, q}}{\mu_{C, q}}\right]
\end{gathered}
$$

where $\sigma_{C, k}$ and $\sigma_{F, k}$ are defined in the same way as for temperature.

From Eqns. $A(12)$ and $A(13)$, the correlation between $X M P_{p}$ and $X M P_{q}$ is :

$$
\rho_{X M P} \approx \frac{\rho_{F} C V_{F, p} C V_{F, q}+\rho_{C} C V_{C, p} C V_{C, q}}{\sqrt{\left(C V_{F, p}^{2}+C V_{C, p}^{2}\right)\left(C V_{F, q}^{2}+C V_{C, q}^{2}\right)}}
$$

where $C V_{\mathrm{C}, k}=\sigma_{\mathrm{C}, k} / \mu_{\mathrm{C}, k}$ and $C V_{F, k}=\sigma_{F, k} / \mu_{F, k}, k=p$, q. Equation $\mathrm{A}(14)$ has the same form as Eqn. A(5), except that the standard deviations are replaced by the coefficients of variation.

The values of $\sigma_{e, i}^{2}$ and $\rho_{e, i}$ were derived from the individual estimates of $\operatorname{var}(X M P)$ and $\rho_{X M P}$ as for temperature, except that no trend was subtracted from the simulated seasonal (resp. annual) values in the future run.

\section{Appendix B: Estimation of $\sigma_{a}^{2}$ and $\sigma_{b}^{2}$}

In the ANOVA model given by Eqn. (3), it is assumed that the $a_{i}$ and the $b_{j}$ are independent random variables with variances $\sigma_{a}^{2}$ and $\sigma_{b}^{2}$, that the variances $\sigma_{e, i}^{2}$ of the noise component $e_{i j}$ may vary over the "emission-scenario AOGCM" clusters and that the RCM simulations in the $i$ th cluster $(i=1, \ldots, A)$ have a correlation $\rho_{e, i}$. In the first instance it is assumed that that there is no correlation between the $e_{i j}$ in different 'emission-scenario AOGCM' clusters.
The means of the sum of squares in Eqns. (5) and (6) can be written:

$$
\begin{aligned}
& \mathrm{E}\left(S S_{1}\right)=\sum_{i=1}^{A} \frac{\operatorname{var} y_{i \bullet}}{n_{i \bullet}}-\frac{\operatorname{var} y_{\bullet \bullet}}{n} \\
& \mathrm{E}\left(S S_{2}\right)=\sum_{i=1}^{A} \sum_{j=1}^{B} n_{i j} \operatorname{var} y_{i j}-\sum_{i=1}^{A} \frac{\operatorname{var} y_{i \bullet}}{n_{i \bullet}}
\end{aligned}
$$

The variance of $y_{i j}$ is given by

$$
\operatorname{var} y_{i j}=\sigma_{a}^{2}+\sigma_{b}^{2}+\sigma_{e, i}^{2}
$$

For the sums $y_{i}$ and $y_{\text {.. }}$ :

$$
\begin{aligned}
& y_{i \bullet}=n_{i \bullet} \mu+n_{i \bullet} a_{i}+\sum_{j=1}^{B} n_{i j} b_{j}+\sum_{j=1}^{B} n_{i j} e_{i j} \\
& y_{\bullet \bullet}=n \mu+\sum_{i=1}^{A} n_{i \bullet} a_{i}+\sum_{j=1}^{B} n_{\bullet} b_{j}+\sum_{i=1}^{A} \sum_{j=1}^{B} n_{i j} e_{i j}
\end{aligned}
$$

with $n_{\bullet j}=\sum_{i=1}^{A} n_{i j}$, the number of simulations with the $j$ th RCM.

Then it follows, for the variances of $y_{i}$ and $y_{\text {:. }}$

$$
\begin{aligned}
& \operatorname{var} y_{i \bullet}= n_{i \bullet}^{2} \sigma_{a}^{2}+n_{i \bullet} \sigma_{b}^{2}+ \\
& \operatorname{var} y_{\bullet \bullet}=\sum_{i=1}^{A} n_{i \bullet, i}^{2}+n_{i \bullet}\left(n_{i \bullet}-1\right) \rho_{e, i} \sigma_{e, i}^{2}( \\
&+\sum_{j=1}^{B} n_{\bullet}^{2} \sigma_{b}^{2}+\sum_{i=1}^{A} n_{i \bullet} \sigma_{e, i}^{2} \\
&+\sum_{i=1}^{A} n_{i \bullet}\left(n_{i \bullet}-1\right) \rho_{e, i} \sigma_{e, i}^{2}
\end{aligned}
$$

Substitution of (B3), (B6) and (B7) into (B1) and (B2) results in:

$$
\begin{aligned}
\mathrm{E}\left(S S_{1}\right)= & \left(n-k_{1}\right) \sigma_{a}^{2}+\left(A-k_{2}\right) \sigma_{b}^{2} \\
& +\frac{1}{n} \sum_{i=1}^{A}\left(n-n_{i \bullet}\right)\left[1+\left(n_{i \bullet}-1\right) \rho_{e, i}\right] \sigma_{e, i}^{2} \\
\mathrm{E}\left(S S_{2}\right)= & (n-A) \sigma_{b}^{2}+\sum_{i=1}^{A}\left(n_{i \bullet}-1\right)\left(1-\rho_{e, i}\right) \sigma_{e, i}^{2}
\end{aligned}
$$

where

$$
k_{1}=\frac{1}{n} \sum_{i=1}^{A} n_{i \bullet}^{2} \text { and } k_{2}=\frac{1}{n} \sum_{j=1}^{\mathrm{B}} n_{\bullet j}^{2}
$$

The estimate $\hat{\sigma}_{b}^{2}$ of $\sigma_{b}^{2}$ is obtained from Eqn. (B9) by replacing $\mathrm{E}\left(S S_{2}\right)$ by $S S_{2}$ and $\sigma_{e, i}^{2}$ and $\rho_{e, i}$ by their estimates from Appendix A:

$$
\hat{\sigma}_{b}^{2}=\frac{1}{n-A}\left[S S_{2}-\sum_{i=1}^{A}\left(n_{i \bullet}-1\right)\left(1-\hat{\rho}_{e, i}\right) \hat{\sigma}_{e, i}^{2}\right]
$$

The estimate is taken to be zero if the right-hand side of Eqn. (B10) is negative. Subsequently $\sigma_{a}^{2}$ is estimated as:

$$
\hat{\sigma}_{a}^{2}=\frac{1}{n-k_{1}}\left\{\begin{array}{l}
S S_{1}-\left(A-k_{2}\right) \hat{\sigma}_{b}^{2}- \\
\left.\frac{1}{n} \sum_{i=1}^{A}\left(n-n_{i \bullet}\right)\left[1+\left(n_{i \bullet}-1\right) \hat{\rho}_{e, i}\right] \hat{\sigma}_{e, i}^{2}\right\}
\end{array}\right.
$$


Again, in the case of a negative value, the estimate is set to zero.

In the derivations above no correlation was assumed between the $e_{i j}$ of different "emission-scenario AOGCM" clusters. For a number of RCMs that have both a simulation for the $\mathrm{A} 2$ and $\mathrm{B} 2$ emission scenario, there is a correlation of about 0.5 because of common control runs. An additional covariance term should therefore be included in the righthand side of Eqn. (B7). This leads to a slightly larger estimate of $\sigma_{a}^{2}$ than the values in Table 5. It has no effect on the estimate of $\sigma_{b}^{2}$. 